\title{
Renda básica universal como programa para um novo reformismo: argumento a partir do caso brasileiro recente de conflito distributivo capital/trabalho
}

\section{Universal basic income as a program for a new reformism: argument from the Brazilian case.}

Pedro Henrique Santos Queiroz ${ }^{1}$ queirozsantoshenriquepedro@gmail.com

\section{Resumo}

O texto sugere, a partir de revisão bibliográfica e de indicadores econômicos, a pertinência do projeto de renda básica universal como horizonte normativo e eixo estratégico para uma ação política moderada de "reformismo forte" (André Singer) ou radical de "reformismo revolucionário" (André Gorz). O diálogo com a literatura disponível sobre renda básica universal é feito a partir de uma leitura da crise final do governo Dilma Rousseff como expressão dos limites do programa reformista fraco de "cidadania salarial" (Robert Castel). Conclui-se pelas vantagens do programa de renda básica universal em termos de capacidade de formulação clara de projetos, discursos de convencimento e orientação estratégica para a ação, seja de uma política reformista forte de redução rápida da pobreza ou reformista revolucionária de transição pós-capitalista.

Palavras chave: renda básica universal; reformismo; crise

\begin{abstract}
The text defends the relevance of the universal basic income project as normative horizon and strategic axis for a moderate political action of "strong reformism" (André Singer) or a radical one of "revolutionary reformism" (André Gorz). The dialogue with the available literature on universal basic income is based on a reading of the final crisis of the Rousseff government as an expression of the limits of the weak reform program of "wage citizenship" (Robert Castel). It is concluded by the advantages of the universal basic
\end{abstract}

\footnotetext{
${ }^{1}$ Doutor em Ciências Sociais pela Universidade Estadual de Campinas (UNICAMP).
} 
Renda básica universal como programa para um novo reformismo: argumento a partir do caso brasileiro recente de conflito distributivo capital/trabalho Pedro Henrique Santos Queiroz.

income program in terms of the ability to formulate projects clearly, discourses of convincing and strategic orientation for action, be it a strong reformist policy of rapid reduction of poverty or revolutionary reformist post-capitalist transition.

Keywords: Universal basic income; reformismo; crisis

\section{A crise atual: uma leitura sobre os limites do programa reformista fraco de cidadania salarial}

Quando Dilma Rousseff foi eleita para seu segundo mandato à frente da Presidência da República, em outubro de 2014, o cenário que se desenhava a partir de alguns dos principais indicadores econômicos era confuso. Os dados de crescimento do PIB mostravam retração já a partir do segundo trimestre, ainda que no agregado dos doze meses o país tivesse "crescido" $0,1 \%$ sobre o ano anterior. Ainda assim, mesmo com a atividade econômica estagnada, o mercado de trabalho continuou a dar sinais de superaquecimento até o último trimestre, com os índices de desemprego mantendo-se excepcionalmente baixos até o último trimestre (4,6\% pela PME e 6,5\% pela PNAD Contínua), e a inflação em alta, chegando no acumulado anual a 6,4\%, bem pouco $(0,9 \%)$ abaixo do teto da meta estabelecida pelo Banco Central ${ }^{2}$.

$\mathrm{Na}$ argumentação que segue, proponho uma leitura do período recente como de esgotamento do programa reformista fraco de aumento do poder de barganha dos trabalhadores pela via da "cidadania salarial". O termo reformismo fraco é usado por André Singer para descrever a estratégia política de baixa confrontação que responde pelo ciclo lento de redução da pobreza e da desigualdade durante os governos de Lula e Dilma, lentidão essa tão mais exasperante quanto são

\footnotetext{
${ }^{2} \mathrm{O}$ documento de maior interesse histórico para a reconstrução do debate sobre esse período pelo pensamento econômico brasileiro de sua própria época é a edição de 09/10/2014 do programa Globo News Miriam Leitão com o então ministro da Fazenda, Guido Mantega e o ex-presidente do Banco Central Armínio Fraga, que havia sido anunciado pelo candidato Aécio Neves (PSDB) como seu ministro da Fazenda em caso de vitória (Globonews, 2014).
} 
Renda básica universal como programa para um novo reformismo: argumento a partir do caso brasileiro recente de conflito distributivo capital/trabalho Pedro Henrique Santos Queiroz.

obscenos os níveis de pobreza e desigualdade dos quais se parte: “(...) o reformismo lulista é lento e desmobilizador, mas é reformismo" (Singer, 2012, p.45).

Ainda no segundo governo Lula, quando da formulação dos objetivos do Programa de Aceleração do Crescimento (PAC) - cuja principal articuladora foi a então ministra Dilma Rousseff, apresentada em palanques por Lula como "mãe do PAC" -, o consenso entre os principais formuladores de estratégia do governo era de que a continuidade da agenda de inclusão social dos governos do PT dependeria de passagem a uma média de crescimento anual do PIB de 5\% (Singer, 2012, p. 160), objetivo ousado já que acima da média das décadas de 1990 (2,5\%) e 2000 (3,6\%).

A escolha estratégica do reformismo fraco pela aceleração do crescimento econômico puxado pelo investimento privado estimulado e coordenado pelo Estado tem como pressuposto teórico e fonte de justificação política o modelo de "cidadania salarial" (a expressão é de Castel, 2007), que vincula a garantia de boa parte dos direitos sociais à relação de emprego clássica e, por via de consequência, estabelece como objetivo principal da política econômica o aumento dos níveis de renda a ser sustentado pelo aumento dos níveis de emprego. Por relação clássica de emprego entenda-se, ainda segundo Robert Castel, o emprego assalariado, fixo, acolhido e regulamentado pelo direito do trabalho e pelas garantias sociais fornecidas pelo Estado.

O investimento privado estimulado e coordenado pelo Estado foi identificado pelos formuladores de política dos governos petistas como principal instrumento capaz de sustentar a aceleração do crescimento porque servia como linha de menor resistência dada a restrição ao aumento do investimento público em um orçamento público que se via espremido entre os juros altos e as política sociais. O legado recebido por Dilma e os desafios que seu governo enfrentaria dali em diante são descritos por Celso Rocha de Barros em artigo de setembro de 2012 para a Revista Piauí nos seguintes termos:

A moderna democracia brasileira nasce justamente na crise do desenvolvimentismo, e convive problematicamente com sua memória. As grandes realizações do Brasil nas últimas décadas foram correções de legados ruins do desenvolvimentismo: a hiperinflação (que só acabou em 1994) e a desigualdade (que só agora caiu abaixo do que era nos anos 60). Por outro lado, o crescimento econômico brasileiro na era democrática foi baixo, bem mais baixo do que no período desenvolvimentista. Por estupenda que tenha sido a vitória de Fernando Henrique Cardoso sobre a inflação, ela se deu ao preço 
Renda básica universal como programa para um novo reformismo: argumento a partir do caso brasileiro recente de conflito distributivo capital/trabalho Pedro Henrique Santos Queiroz.

de o Brasil ter a maior taxa de juros do mundo. E, por mais indiscutivelmente justas que sejam as políticas sociais de Lula, é fato que mais dinheiro para a área social é menos dinheiro para investimento. Isto é: a herança que Dilma recebeu de seus antecessores inclui a prataria, mas também aquele quadro feio de palhaço chorando (Barros, 2012).

É grande a lista de medidas que foram tentadas sucessivamente para dar um boost no investimento privado: redução da taxa de juros, redução da carga tributária via desonerações setoriais, aumento do volume de crédito subsidiado por bancos públicos, intervenção na taxa de câmbio, administração de preços de eletricidade e combustíveis, adoção de políticas de conteúdo nacional na compra das empresas estatais e manutenção em alta da demanda interna via manutenção em alta do consumo das famílias (seja pelo emprego em alta, seja pelas facilidades de acesso a crédito para o consumo popular). Esse conjunto de medidas ficou conhecido pela expressão "Nova Matriz Econômica”, usada pelo ministro da fazenda Guido Mantega no título do artigo"O primeiro ano da nova matriz econômica ${ }^{3 ",}$ de dezembro de 2012 para o jornal Valor Econômico:

Um mundo novo de oportunidades vai surgir para aqueles que querem ver seu capital se expandir, mas, desta vez, capitaneado pela produção. A atividade financeira vai se adaptar e encontrar os caminhos da rentabilidade apoiando a atividade produtiva. A era do ganho fácil e sem risco ficou para trás, apesar do choro e ranger de dentes dos poucos que se beneficiavam dessa situação (Mantega, 2012)

O investimento privado, no entanto, não reagiu como esperado. Para ficarmos com apenas um dos indicadores disponíveis: a taxa de investimento nominal, calculada pelo IPEA a partir da formação bruta de capital fixo ${ }^{4}$, variou entre 15 e $20 \%$ do PIB, mantendo o padrão observado desde o início da série histórica em 1996: partindo de 17,30\%, no início de 2007,

\footnotetext{
${ }^{3}$ É questionável que a Nova Matriz Econômica tenha apresentado algum elemento de política de esquerda, mesmo reformista.

4 “A formação bruta de capital fixo (FBCF) da economia é composta pelos investimentos em: máquinas e equipamentos; construção civil; e por outros ativos fixos (como propriedade intelectual, lavouras permanentes, gado de reprodução, etc.)" (IPEA, 2017).
} 
Renda básica universal como programa para um novo reformismo: argumento a partir do caso brasileiro recente de conflito distributivo capital/trabalho Pedro Henrique Santos Queiroz.

quando foi lançado oficialmente o PAC, até atingir o pico no terceiro semestre de 2013 (21,56\%) - segundo maior valor da série -, e seguindo uma trajetória ladeira abaixo, chegando a 16,28\% no terceiro trimestre de 2016, quando foi concluído o processo de afastamento da presidenta Dilma.

O custo fiscal elevado das medidas de estímulo ao desenvolvimento, sobretudo a partir da Nova Matriz, contribuiu para a deterioração da relação dívida/PIB e piorou as expectativas dos agentes, deprimindo ainda mais o investimento privado e gerando um ciclo vicioso, o que supostamente não teria acontecido caso os objetivos de estímulo ao investimento tivessem sido alcançados, já que a massa tributável teria crescido proporcionalmente. Só em desonerações foram R $\$ 458$ bilhões em frustração de receitas projetadas até 2018, segundo cálculo de auditores da Receita Federal consultados por uma reportagem da Folha de São Paulo (Folha de São Paulo, 2015). Esse valor é 25\% superior ao despendido pelos Estados Unidos no Plano Marshall de reconstrução da Europa destruída pela segunda guerra mundial, como mostrou Samuel Pessôa ao atualizar os valores e compará-los por poder de compra e câmbio (Pessôa, 2017).

A pergunta que fica é por que, afinal de contas, o capitalismo brasileiro se mostrou incapaz de dar o salto requerido para a manutenção do ritmo de inclusão social dos governos petistas?

A dificuldade na busca de respostas a questões desse tipo está na incapacidade de evitar os desfiladeiros e caminhos sinuosos entre o núcleo duro que constitui a economia como ciência positiva (capaz de observação de regularidades empíricas e proposição de leis gerais) e seu invólucro gorduroso de ideologia burguesa (vulnerável a proposições irrefletidas sobre a natureza humana e a vida em sociedade). A dificuldade de avanço nesse terreno é a de determinar quando e em que medida a escolha racional dos agentes econômicos é de reação adaptativa às informações que recebem do mercado ou mera imposição de vontade irracional do lado mais forte em uma relação desigual e injusta (principal exemplo as concentrações "economicamente inúteis" de renda e riqueza de que fala Piketty, 2014). 
Renda básica universal como programa para um novo reformismo: argumento a partir do caso brasileiro recente de conflito distributivo capital/trabalho Pedro Henrique Santos Queiroz.

Sem pretender cobrir todo os aspectos contemplados pelo rico debate atualmente em curso no pensamento econômico brasileiro $^{5}$ e para meros fins de exposição de um modelo simplificado de conflito distributivo capital/trabalho, é possível levantar dois grandes grupos de explicações para o fracasso das medidas de estímulo ao investimento privado a partir da nova matriz econômica. Quais sejam:

a) Problemas técnicos de formulação e execução das políticas de estímulo. Aqui entram desde questões relativas ao caso a caso de cada setor, como a intervenção desastrosa nos setores energético e sucroalcooleiro, até questões mais transversais, como a ausência de mecanismos mais bem pensados de exigência de contrapartida pelas empresas que se beneficiaram do acesso a crédito subsidiado em bancos públicos e das políticas de desoneração. Outra crítica recorrente no debate especializado foi a de que os estímulos deveriam ter sido oferecidos de forma linear, isto é para o conjunto dos agentes econômicos, e não, como efetivamente foi feito, selecionando empresas com potencial de tornarem-se "campeãs nacionais", o que é verdadeiro para a parte dos empréstimos em bancos públicos e desonerações, responsáveis diretos pela maior parte do rombo fiscal, mas não para outras medidas que afetaram a todos igualmente, como foi o caso da queda dos spreads bancários, o posicionamento mais competitivo do câmbio, o maior dinamismo do mercado consumidor interno e a redução do preço de combustível e eletricidade.

b) A aparente resistência cultural do capitalismo brasileiro a empreender em condições outras que não a de ampla disponibilidade de força trabalho barato e submisso, o que talvez se explique pelas circunstâncias históricas de formação do mercado de trabalho livre no Brasil após quase quatro séculos de escravidão. Sobre esse ponto, cabe lembrar que o trabalho escravo (a propriedade jurídica do portador da força de trabalho por outrem) foi abolido tardiamente no Brasil e sem garantia de indenização de qualquer tipo aos ex-escravos e seus descendentes. Além

\footnotetext{
5 Para uma amostra representativa do estado atual do debate entre economistas ortodoxos e heterodoxos a respeito da interpretação do período da nova matriz, ver os artigos listados na postagem "Um ano de blog do IBRE: Os artigos mais lidos" no blog do Instituto Brasileiro de Economia (IBRE/FGV, 2018).
} 
Renda básica universal como programa para um novo reformismo: argumento a partir do caso brasileiro recente de conflito distributivo capital/trabalho

Pedro Henrique Santos Queiroz.

disso, no caso brasileiro a separação entre força de trabalho e propriedade dos meios de produção - pressuposto histórico necessário para a existência de um mercado de trabalho livre foi garantida pelo surgimento da questão agrária como resposta política das elites à necessidade de manutenção de excedentes disponíveis de força de trabalho barato nas lavouras, como indicado pela quase concomitância em 1850 das promulgações da Lei de Terras, que restringia o acesso à propriedade da terra, e da Lei Eusébio de Queiroz, que proibia a importação de escravos: "Se no regime sesmarial, o da terra livre, o trabalho tivera que ser cativo; num regime de trabalho livre a terra tinha que ser cativa"(Martins, 2010, p. 44)

Admitindo-se que os fatores do segundo grupo tenham algum peso explicativo para a crise política atual, um dos fenômenos mais importantes a destacar para a compreensão histórica do período dos governos do PT na Presidência é a tendência de aumento do poder de barganha dos trabalhadores sobre a determinação das condições de venda da mercadoria força de trabalho. A trajetória de redução acíclica do desemprego, que se inicia em meados de 2003 e atinge o zênite em 2014 (com o crescimento do PIB estagnado, lembremos), resultou no fortalecimento da posição dos trabalhadores no jogo de oferta e procura no mercado de trabalho. É uma trajetória acíclica porque, como mostraram Alves e Correa (2013), a redução da taxa de desocupação foi pouco afetada pelas oscilações em utilização da capacidade instalada, crescimento do PIB e produção industrial no período.

Outra força a pressionar para cima o preço do trabalho foi a redução da pobreza, que significou retirada de parte dos "incentivos" gerados pela vulnerabilidade social extrema para a oferta de mão de obra barata e dócil ${ }^{6}$.

São evidências do aumento do poder de barganha do trabalho frente ao capital nesse período a) para a população em geral, o crescimento da renda das famílias acima do crescimento

\footnotetext{
6 Pelo critério dos Objetivos de Desenvolvimento do Milênio, das Nações Unidas - que define a pobreza extrema usando o patamar de US\$1,25/dia - a pobreza extrema no Brasil caiu de uma taxa de 9,37\% em 2004 para 3,09\% em 2014.
} 
Renda básica universal como programa para um novo reformismo: argumento a partir do caso brasileiro recente de conflito distributivo capital/trabalho Pedro Henrique Santos Queiroz.

do $\mathrm{PIB}^{7}$ e b) para os setores organizados em sindicatos, a maior frequência de reajustes acima da inflação (medida pelo INPC) nas negociações salariais monitoradas pelo DIEESE ${ }^{8}$.

Em 31 de agosto de 2016, quando do afastamento definitivo de Dilma Rousseff pelo Senado, os indicadores de mercado de trabalho indicavam desaquecimento compatível com a retração da atividade econômica: o PIB acumulava oito trimestres de crescimento negativo, indicando, no agregado anual, retração de 3,6\% após queda de 3,8\% no ano anterior. O desemprego estava em alta (11,8\% pela PNAD Contínua $\left.{ }^{9}\right)$ e a inflação desacelerava e começava a retroceder, vindo a terminar o ano abaixo do teto da meta, após ter estourado a meta no ano anterior e permanecido acima do teto durante a maior parte de 2016.

A deterioração dos níveis de emprego veio a partir de 2015 em meio a um cenário político nacional de esgotamento seguido de ruína do arranjo político que havia sustentado até então a configuração do conflito entre capital e trabalho com vantagem relativa para o trabalho. Não sendo possível ou mesmo desejável entender a capacidade de ação política dos trabalhadores como função tão somente de sua posição relativa de força no mercado de trabalho, parece pertinente buscar alternativas às debilidades de projeto, estratégia e discurso das esquerdas que atualmente dificultam que o acirramento do conflito entre capital e trabalho consiga se manifestar enquanto tal e em algum sentido politicamente construtivo.

Os tempos da transição: renda básica universal como horizonte normativo e eixo estra tégico para um novo reformismo

São várias e bem distribuídas ao longo do tempo e do espectro político esquerda/direita as propostas do direito a uma renda universal. Uma definição mais geral e comum às várias propostas disponíveis é a de garantia do direito universal a uma renda (mínima ou básica), sem

\footnotetext{
7 De 2003 a 2011 o crescimento acumulado da primeira variável foi de 40,7\%, enquanto que o da segunda ficou em $27,7 \%$ (IPEA, 2012).

${ }^{8}$ No melhor momento, alcançado em 2012, 93,6\% das negociações resultaram em ganhos reais (DIEESE, 2016).

9 A Pesquisa Mensal de Emprego (PME) citada no primeiro parágrafo desse texto, foi descontinuada em fevereiro de 2016.
} 
Renda básica universal como programa para um novo reformismo: argumento a partir do caso brasileiro recente de conflito distributivo capital/trabalho Pedro Henrique Santos Queiroz.

exigência de contrapartida em trabalho, via transferência direta por parte do Estado de uma determinada quantia a todos e cada um dos participantes de uma determinada comunidade jurídica. Os antecedentes dessa ideia na tradição ocidental remontam pelo menos à Utopia de Thomas More, no século XVI, e desde então a ela chegaram, muitas vezes por vias independentes ${ }^{10}$, vários pensadores e reformadores sociais envolvidos com os problemas de pobreza e desigualdade a partir de inclinações políticas bastante diversas. É possível encontrar aí desde a concepção neoliberal de um imposto de renda negativo (Milton Friedman) até o programa de renda básica universal como transição para o socialismo (como em André Gorz e nos primeiros escritos de Van Parijs). Umas das principais propostas do debate atual - e aquela que é defendida nesse texto - é o modelo proposto pela Rede Internacional de Renda Básica (Basic Income Earth Network - BIEN), que define-se por cinco características: pagamento periódico, em dinheiro, individual, universal e incondicional.

No período recente, posições pró renda básica universal vêm ganhando espaço no debate internacional mainstream. A multiplicação de projetos piloto de renda básica em diversos países (só no ano de 2016, foram registradas a implantação ou planejamento de iniciativas do tipo nos seguintes países: Finlândia, Canadá, Quênia, Holanda, Escócia, Uganda, e Estados Unidos) (BIEN, 2017) é indicativa de um interesse crescente dos formuladores de políticas públicas por alternativas capazes de lidar com a persistência e agravamento dos problemas de desigualdade social pós crise de 2008. Outro destaque do debate no período recente tem sido o apoio entusiasmado a propostas de renda básica por parte de investidores do setor de alta tecnologia do Vale do Silício preocupados com as possíveis consequências de desemprego tecnológico pela disseminação de inovações distuptivas como inteligência artificial e impressoras 3D.

\footnotetext{
${ }^{10}$ Um dos casos mais intrigantes é o relatado por Eduardo Suplicy, que em conversa com o governador do Alasca (onde desde 1982 funciona um programa de renda universal), descobriu que este nunca ouvira falar das ideias de Thomas Paine sobre o assunto, sendo que esse founding fahter dos Estados Unidos é considerado autor de uma das primeiras formulações modernas do direito à renda universal. (Suplicy, 2013, p. 136)
} 
Renda básica universal como programa para um novo reformismo: argumento a partir do caso brasileiro recente de conflito distributivo capital/trabalho Pedro Henrique Santos Queiroz.

No Brasil, o debate sobre renda básica tem sido pautado principalmente pela atuação do ex senador e hoje vereador por São Paulo Eduardo Matarazzo Suplicy (PT), responsável pela inclusão no ordenamento jurídico brasileiro (Lei 10.835/2004) do programa de renda básica de cidadania como orientação de longo prazo para políticas de transferência de renda.

A adoção de um programa de renda básica universal abre amplas possibilidades tanto para a reelaboração de uma estratégia de reformismo forte, de diminuição da pobreza e da desigualdade em ritmo acelerado e com mobilização política crescente, como de reformismo revolucionário, de superação do patamar de barganha por melhores condições de venda da mercadoria força de trabalho para o questionamento da condição de obrigatoriedade de venda dessa mercadoria em um mercado capitalista. A seguir, busca-se expor as vantagens da incorporação da bandeira por renda básica universal para as estratégias de reformismo forte ou revolucionário em termos de definição clara de programas de governo, capacidade de formulação de discursos de convencimento e identificação de objetivos estratégicos que norteiem a ação política para além dos aspectos muitas vezes comezinhos da disputa política cotidiana.

Para a formulação do programa de reformismo forte, não necessariamente comprometido com a superação do modo de produção capitalista, o programa de renda básica universal permite uma alternativa ao paradigma de pleno emprego (full-employment) como principal meio de garantia de direitos sociais. Mudanças de ordem geopolítica, como o fim da guerra fria e a globalização com forte assimetria de condições de mobilidade entre capital e trabalho explicam em parte o aumento dos custos fiscais e político do pleno emprego. Nessas condições, são grandes as dificuldades encontradas por governos de todo o mundo em "convencer" o grande capital a submeter-se a condições de tributação progressiva ou de coordenação para o desenvolvimento nacional. Além disso, a fragmentação espacial da produção e a tendência de aumento da participação do setor de serviços na formação do PIB, são fatores de dificuldade para a reprodução do arranjo predominante durante os "30 anos dourados" (do final da segunda guerra mundial aos primeiros choques de preço de petróleo no início da década de 1970), período de expansão dos direitos sociais sob o "binômio taylorismo-fordismo/welfare state" (Antunes, 2005). 
Renda básica universal como programa para um novo reformismo: argumento a partir do caso brasileiro recente de conflito distributivo capital/trabalho Pedro Henrique Santos Queiroz.

No caso brasileiro, os custos fiscais da política de garantia de pleno emprego e sua desvantagem em relação a uma política de renda básica universal podem ser considerados por uma rápida olhada nos números. O total de benefícios fiscais chegou em 2016 a 6,2\% do PIB (Estado de São Paulo, 2015), enquanto que os custos estimados de uma política de renda mínima universal no valor de $\mathrm{R} \$ 1.286$ por ano (aproximadamente $\mathrm{R} \$ 107$ por mês) seriam de 4,6\% do PIB (Valor Econômico, 2017). Já os custos políticos são evidenciados pela pouca ou nenhuma exigência de contrapartida com que foram feitas a maior parte das políticas de estímulo ao desenvolvimento e, de forma anedótica, pelo gigantesco pato amarelo inflado pela Federação das Indústrias do Estado de São Paulo (FIESP), um dos principais símbolos adotados pelas manifestações de rua pela deposição de um governo que havia concedido quase todos os pontos de política econômica pleiteados por essa entidade ${ }^{11}$.

A decisão no início do primeiro governo Lula de unificar sob o Bolsa Família e ampliar bastante a abrangência e orçamento dos vários programas federais de transferência direta de renda aos mais pobres que haviam sido implantados de forma um tanto assistemática durante os governos FHC é surpreendente se considerarmos as afinidades do programa petista com o programa de cidadania salarial (o nome do partido, é bom lembrar, é "dos trabalhadores") e a posição majoritária naquele momento entre intelectuais do partido contrários ao programa por seu desenho focalista. Que Lula tenha dado ganho de causa nessa questão aos colaboradores neoliberais que haviam sido trazidos ao governo por seu ministro da fazenda Antônio Palocci notadamente Marcos Lisboa e Ricardo Paes de Barros - é algo que talvez possa ser atribuído à sua origem de classe: antes de torneiro mecânico formado pelo Senai e líder sindical surgido da estrutura de representação burocrática herdada do período varguista, Lula foi pau-de-arara e conheceu de perto o horror inominável da miséria ${ }^{12}$.

\footnotetext{
11 Para uma análise do documento "Brasil do diálogo, da produção e do emprego", assinado em conjunto pela Central Única dos Trabalhadores (CUT), Força Sindical e FIESP ver Singer, 2015, p 54-56.

12 Para uma reconstituição do clima desse debate nos bastidores do primeiro governo Lula, ver a troca de artigos entre Fernando Haddad (2017) e Marcos Lisboa (2017) promovida pela revista Piauí.
} 
Renda básica universal como programa para um novo reformismo: argumento a partir do caso brasileiro recente de conflito distributivo capital/trabalho

Pedro Henrique Santos Queiroz.

O termo "reforma revolucionária” é usado por André Gorz (2004) para designar o projeto de renda básica universal e marca com precisão a natureza paradoxal de uma demanda que é reformista porque, a rigor, plenamente compatível com os pressupostos da propriedade privada dos meios de produção e da livre negociação entre as partes interessadas, porém que na prática representaria forte estímulo ao desenvolvimento de formas de socialização (não necessariamente estatização) dos meios de produção. Isso porque a instituição de uma política de renda básica universal não implicaria em abolição de toda e qualquer forma de assalariamento ou propriedade privada dos meios de produção porque por si só não implica em nenhum tipo de objeção à livre negociação entre partes interessadas na compra e venda da mercadoria força de trabalho. Por outro lado, a eliminação das formas mais extremas de compulsão ao trabalho assalariado -garantidas pela existência de um grande exército industrial de reserva que pressiona para baixo o preço da força de trabalho - e o fortalecimento das condições de barganha dos trabalhadores daí decorrente poderia ser aproveitado por uma estratégia política de reivindicação de maior poder de decisão dos trabalhadores sobre o processo de trabalho (sua organização e finalidade), colocando, assim, em questão o despotismo dos proprietários dos meios de produção e organizando a transição para um modo de vida pós-capitalista.

Ainda em chave reformista revolucionária, a instituição da renda básica permite tornar mais explícito o conflito entre tempo livre, tempo de trabalho (produção de coisas socialmente úteis) e tempo de trabalho para o capital. A colocação do problema nesses termos facilitaria a luta contra a deformação do desenvolvimento das forças produtivas pela irracionalidade capitalista, segundo a qual os ganhos de produtividade (aumento da capacidade humana de fazer mais coisas em menos tempo) tenham como resultado menos postos de trabalho e aumento das jornadas de trabalho e não - como poderia ser mas não é - em mais postos de trabalho e jornadas de trabalho menores. Dessa perspectiva, umas das principais vantagens do argumento pró-renda básica está na explicitação da diferença entre o trabalho como atividade de produção de coisas socialmente úteis (i.e que atendam a alguma necessidade social, qualquer que seja, "do estômago ou da fantasia") e o trabalho como meio para a valorização do capital (o primeiro subordinado ao 
Renda básica universal como programa para um novo reformismo: argumento a partir do caso brasileiro recente de conflito distributivo capital/trabalho Pedro Henrique Santos Queiroz.

segundo como o trabalho concreto é subordinado ao trabalho abstrato nos termos usados por Karl Marx no livro I de O Capital). Para ficarmos com o exemplo de André Gorz, muito esclarecedor sobre esse ponto, o questionamento a ser feito é por que se diz que "uma mulher 'não tem trabalho', embora consagre seu tempo a criar seus filhos, e que ela 'tem um trabalho' quando consagra uma fração de seu tempo a criar os filhos alheios numa creche ou numa escola maternal?” (Gorz, 2004, p.10)

A qualidade de clareza retórica intrínseca ao argumento em favor da renda básica e seu favoritismo na discussão racional de ideias em espaço público transparecem também no embate com a ideologia meritocrática de justificação moral das desigualdades. Isso porque, se é possível ainda que com alguma dificuldade - sustentar a opinião de que os muito ricos merecem usufruir de sua imensa riqueza, é, no entanto, muito difícil não deslizar para algum tipo de argumentação autoritária e obscurantista ao sustentar que alguém - quem quer que seja esse alguém - merece ter que pedir dinheiro a pessoas desconhecidas na rua por não ter o que comer.

Seja de uma perspectiva de reformismo forte ou revolucionário, a opção pela renda básica universal permite a orientação de uma estratégia política capaz de esclarecer o estabelecimento de objetivos de curto, médio e longo prazo, a partir dos quais seria possível extrair parâmetros de avaliação de movimentos de avanços, recuos táticos, possibilidades de aliança ou oposição com as diversas forças atuantes no jogo político. De forma esquemática, é possível pensar em uma construção por etapas: no curtíssimo prazo o objetivo é acabar com a pobreza absoluta. Para tanto, não deve existir qualquer tipo de constrangimento para acordos táticos com o programa neoliberal de renda mínima, tomando o cuidado de manter em aberto o debate sobre todos os demais aspectos da relação entre Estado e sociedade civil (tamanho da carga tributária, participação do Estado na atividade econômica e oferecimento de serviços públicos etc). A argumentação de convencimento dirigida a esse aliados de ocasião provavelmente seguiria a linha da maior eficiência do gasto com renda básica, afinal 
Renda básica universal como programa para um novo reformismo: argumento a partir do caso brasileiro recente de conflito distributivo capital/trabalho Pedro Henrique Santos Queiroz.

(...) se o objetivo é mitigar a pobreza, deveríamos ter um programa destinado a ajudar o pobre. Há muitas razões para justificar a ajuda ao pobre que acontece ser um fazendeiro - não porque é fazendeiro, mas porque é pobre (Friedman, 1977, p. 162).

No curto e médio prazo, vencida a pobreza absoluta, os objetivo principais passam a ser de redução das desigualdades de renda e riqueza e aumento da igualdade de oportunidades. Ainda aí é possível pensar em aliança tática com os liberais que se dispuserem a enfrentar a insatisfação das elites de mentalidade pré-capitalista com o sumiço da ampla oferta de trabalho barato. Os argumentos de convencimento que poderiam cimentar essa última coalisão possível entre reformistas e neoliberais seriam, para ficarmos em um exemplo caro ao caso brasileiro, de demonstração do enorme desperdício de recursos, em termos de custo de oportunidade, implicado na quantidade injustificada de tempo de vida perdido por mulheres (sobretudo de pele negra ou parda) em atividades de serviço doméstico mal remunerado. No longo prazo, a perspectiva reformista revolucionária é de transição para o socialismo. A fim de não repetir os erros do estatismo de tipo soviético, o desafio a ser assumido consiste em tentar se antecipar ao curso provável dos acontecimentos e se posicionar de forma a aproveitar a pressão do aumento do preço do trabalho sobre a propriedade privada dos meios de produção para desenvolver (o que em muitos casos significa descobrir ou inventar mesmo) formas que possam substituir o cálculo econômico capitalista como mecanismo de coordenação e divisão do trabalho social.

A viabilização de um programa de renda básica com valores mais robustos (algo acima do valor de R\$ 1.286/ano usado no estudo do FMI para o caso brasileiro), oferece desafios apreciáveis para a definição de diretrizes de um plano de governo reformista. Além da complexidade das escolhas sobre a própria definição efetiva de política pública de renda básica (definição jurídica do sujeito de direito, valor e periodicidade do benefício etc), uma iniciativa desse tipo, possivelmente terá que pensar em meios para evitar ou minorar problemas econômicos de desajuste entre oferta e demanda agregadas, como por exemplo de desabastecimento ou aceleração inflacionária. Outro problema prático a ser enfrentado - esse de solução mais explicitamente política do que de lógica interna de funcionamento dos mercados 
Renda básica universal como programa para um novo reformismo: argumento a partir do caso brasileiro recente de conflito distributivo capital/trabalho Pedro Henrique Santos Queiroz.

- é o de adequação ao orçamento público. Como financiar um programa de renda básica universal? Pela criação de fundos públicos específicos para essa finalidade (como é feito atualmente no Alasca $\left.{ }^{13}\right)$ ? De onde viriam os recursos para esse fundo? De alguma fonte de receita extraordinária? Ou da realocação de recursos destinados a outros itens do orçamento atualmente disponível? Será necessário algum aumento (e de quanto?) de arrecadação de impostos, emissão de moeda ou de títulos da dívida pública?

As especificações da Lei 10.835/2004, proposta por Suplicy, oferecem uma boa base a partir da qual estruturar uma resposta reformista forte ou revolucionária aos desafios de adequação ao orçamento público e equilíbrio macroeconômico. São instrumentos importantes nesse sentido as especificações previstas nesse texto legal, que define um desenho de implantação gradual e com transição para o universalismo focalizando inicialmente nos mais pobres ${ }^{14}$, "considerando para isso o grau de desenvolvimento do País e as possibilidades orçamentárias".

Dentro desses parâmetros dados pelo texto legal, é possível pensar em vários tipos de medidas para a viabilização de um programa de renda básica universal a serem implementadas em arranjos e proporções diversas a depender das diferentes escolhas de orientação política reformista forte ou revolucionária. Pelo lado da oferta: A) Políticas de incentivo ao cooperativismo e pequeno empreendedorismo; B) Melhor alocação do estoque disponível de força de trabalho que as pessoas agora não mais pressionadas por situações extremas de vulnerabilidade se dispuserem a oferecer no mercado. Políticas de formação e reciclagem profissional entrariam aqui como forma de apoio para que o aumento do preço da força de trabalho implique em deslocamento desse recurso de atividades de baixa produtividade (novamente, o trabalho doméstico mal remunerado é o melhor exemplo para o caso brasileiro) em direção a atividades de mais alta produtividade e C) Investimento em ciência e tecnologia com

\footnotetext{
13 A referência ao caso do Alasca deve ser sempre tomada com cautela no debate devido às especificidades desse Estado de pequena população, com enormes reservas de petróleoe com autonomia garantida pelo federalismo norte americano para distribuir as rendas provenientes dos Royalties de Petróleo

${ }^{14}$ Na primeira versão desse projeto de Lei, o foco eram os cidadãos mais idosos. Essa característica foi mudada ainda nas primeiras rodadas de debate parlamentar. Para uma reconstrução analítica dessa discussão, ver Silva, 2014.
} 
Renda básica universal como programa para um novo reformismo: argumento a partir do caso brasileiro recente de conflito distributivo capital/trabalho Pedro Henrique Santos Queiroz.

foco em inovações poupadoras de tempo de trabalho. Já pelo lado da demanda as medidas seriam de: A) Maior difusão de conceitos de educação financeira e economia doméstica via campanhas de comunicação social e valorização desses itens nos currículos dos programas de educação formal e B) Estímulo à desmercantilização de atividades e formas de cooperação que compõem a moderna divisão social do trabalho, com o objetivo de estimular mudanças de mentalidade e hábitos culturais ligados a padrões de consumo promovendo outras formas de satisfazer as várias necessidades sociais que não apenas pela relação de troca mercantil.

Quanto à questão do financiamento: cada umas das escolhas de política fiscal envolvem algum tipo de trade-off e, por essa razão, a melhor forma de encaminhá-las é pela deliberação coletiva de natureza democrática. Não há como escapar em decisões desse tipo à tomada de posições valorativas e ao estabelecimento de critérios sobre as necessidades que devem ser atendidas prioritariamente pelo orçamento público, o que, por sua vez, remete diretamente à escolha existencial sobre o tipo de sociedade em que queremos viver. Tão somente como aperitivo para essa discussão, que não cabe aprofundar aqui, considere-se por um instante os valores do gasto anual em 2016 com bolsa família (29 bilhões, aproximadamente $0,5 \%$ do PIB) e com o judiciário brasileiro (75 bilhões, 1,4\% do PIB, sendo 89\% desse valor destinado a custos de recursos humanos) (Conselho Nacional de Justiça, 2017). Ainda que não existam soluções mágicas, a questão sobre a viabilidade fiscal de um programa de renda básica universal é - e não tem como deixar de ser - uma questão de formação de vontade política. Como exposto por Guy Standing na sessão A Basic Income for All: Dream or Dellusion do Fórum Econômico Mundial de Davos em 2017: também parecia não haver condições orçamentárias para salvar o sistema financeiro pós crise de 2008, o que, no entanto, de alguma forma, foi feito (World Economic Forum, 2017).

\section{Renda Básica Universal como forma de reconhecimento}

Toda a argumentação pró-renda básica universal até aqui desenvolvida nesse texto foi feita nos termos de um ideal restrito de justiça distributiva e tendo como pressuposto um modelo 
Renda básica universal como programa para um novo reformismo: argumento a partir do caso brasileiro recente de conflito distributivo capital/trabalho

Pedro Henrique Santos Queiroz.

simplificado do conflito de interesses entre compradores e vendedores da mercadoria força de trabalho. Embora exercícios analíticos como esse que foi tentado tenham interesse como imaginação sociológica, os limites de seu alcance explicativo ficam evidentes na pobreza do relato que daí sobressai sobre a disputa política por um programa de renda básica universal, como se esse processo de deliberação coletiva pudesse ser satisfatoriamente descrito como uma uma série de escaramuças retóricas entre reformistas, ideólogos da meritocracia e tecnocratas neoliberais.

Para um relato mais realista da luta política pelo direito a uma renda básica universal, seria preciso ampliar a noção de conflito distributivo para além da luta entre capital e trabalho, inserindo aí desigualdades (principalmente, mas não apenas) de raça e sexo/gênero. E, para além do conflito distributivo, seria preciso considerar também questões de reconhecimento moral, isto é aqueles problemas referentes à definição da identidade de si mesmas que as pessoas fazem ao estabelecerem relações umas com as outras. Seria desejável ainda algum nível de esclarecimento teórico sobre a natureza da ligação entre questões de justiça distributiva e de reconhecimento moral. Nesse sentido, a atual rodada de debates na teoria crítica é de particular interesse para uma definição reformista (forte ou revolucionária) do programa de renda básica universal.

A questão, tal como posta nos termos desse debate, é se os termos de justiça distributiva podem ser derivados dos de reconhecimento moral, como entende Axel Honneth (isto é, a má distribuição é causada por reconhecimento moral insuficiente), ou se ambos os princípios de justiça são co-fundamentais e, portanto, não redutíveis um ao outro, como indica Nancy Fraser (Silva, 2008, p. 94). Em termos de orientação estratégica para a ação política, esse dilema se traduz no desacordo sobre se as reivindicações de justiça devem ter por objetivo principal o estabelecimento de condições paritárias de decisão (Fraser) ou a auto realização prática de sujeitos capazes de auto respeito, autoestima e autoconfiança (Honneth) (Honneth e Fraser, 2003, p. 12).

Dentre as várias formas de arranjo possível entre as categorias de justiça para a orientação normativa e estratégica da ação política, um dos caminhos que parece mais promissores é aquele aberto pela escolha da emancipação como categoria capaz de atravessar as diversas lutas sociais e 
Renda básica universal como programa para um novo reformismo: argumento a partir do caso brasileiro recente de conflito distributivo capital/trabalho Pedro Henrique Santos Queiroz.

definir um horizonte ainda mais amplo do que o socialismo prometido pelo reformismo revolucionário:

(...) emancipação pode significar tanto a autonomia individual, no sentido das possibilidades que uma pessoa tem para desenvolver plenamente suas capacidades, como a autodeterminação de uma coletividade para se organizar autônoma e cooperativamente de uma maneira condizente com a condição humana (Silva, idem, p. 140)

Além do mérito de versatilidade teórica, apontado por Josué Pereira da Silva, é possível pensar que o uso da categoria-síntese emancipação - sobretudo se essa for substituída por um sinônimo de uso mais comum, como libertação- pode ajudar na difusão e enraizamento da reivindicação por renda básica universal na vida política brasileira, facilitando sua capacidade de aproveitamento da memória histórica de outros momentos de luta por direitos e melhorando suas condições de diálogo com linhagens já estabelecidas de exercício prático da autonomia, como, por exemplo, os princípios do método Paulo Freire de alfabetização de adultos e da Teologia da Libertação.

Em termos práticos, a demanda por reconhecimento moral implícita na proposta de renda básica universal está na promoção de um entendimento mais substantivo de cidadania, seja como como acesso a direitos para o auto-desenvolvimento (como em Honneth), seja de garantia de condições materiais de participação efetiva (como em Fraser), aproximando, assim, uma maior parte da população da realização efetiva de seu direito a ter direitos.

\section{Conclusões}

O esgotamento do arranjo político que manteve uma situação de vantagem relativa das condições de barganha dos trabalhadores até meados de 2014 foi interpretado nesse texto como indicativo dos limites das politicas de reformismo fraco (Singer) que se basearam em tentativas de estimulo ao investimento privado como meio de garantir a expansão dos níveis de emprego e renda. Nesse sentido, destacou-se o alto custo político e fiscal das políticas de incentivo ao capital 
Renda básica universal como programa para um novo reformismo: argumento a partir do caso brasileiro recente de conflito distributivo capital/trabalho Pedro Henrique Santos Queiroz.

privado ("Nova Matriz Econômica") sem que os resultados esperados tivessem sido obtidos. A de renda básica universal foi aqui apresentada como alternativa possível às escolhas do reformismo fraco, destacando vantagens dessa política em termos de clareza programática, orientação estratégica para a ação e capacidade de convencimento para uma estratégia alternativa, seja ela de orientação reformista forte (Singer) ou reformista re volucionária (Gorz).

Para além do conflito distributivo entre compradores e vendedores da mercadoria força de trabalho, indicou-se também a necessidade de ancorar a reivindicação por renda básica universal em uma demanda mais ampla por reconhecimento moral, indicando-se, nesse sentido, a conveniência da categoria emancipação (ou libertação) articulador discursivo mais capaz de equilibrar as demandas de distribuição/reconhecimento e promover um diálogo mais fecundo com linhagens de prática da autonomia já estabelecidadas na cultura política brasileira.

\section{Referências bibliográficas}

ALVES, S. A e CORREA, A S. 2013 Um Conto de Três Hiatos: desemprego, utilização da capacidade instalada da indústria e produto. Trabalhos para Discussão - Banco Central do Brasil, n 339: p. 1-42.

ANTUNES, R. 2005. Os Sentidos do Trabalho. Ensaio sobre a afirmação e a negação do trabalho. 1 ed. São Paulo, Boitempo.

Basic Income Earth Network (BIEN). 2017. Current basic income experiments (and those so called): na overview. Disponível em

https://basicincome.org/news/2017/05/basic-income-experiments-and-those-so-called-early-20 17-updates/. Acessado em 28/05/2018

BARROS, C. R.. 2012. O Estilo Dilma na hora H. Revista Piauí. Disponível em http://piaui.folha.uol.com.br/materia/o-estilo-dilma-na-hora-h/. Acessado em 28/05/2018 CASTEL, R.. 2007 Au-delà du salariat ou en deçà de l'emploi : L'institutionnalisation du précariat. In PAUGAM, S. (Org) Repenser la solidarité. Paris, Presses Universitaires de France, p. 415-43. 
Renda básica universal como programa para um novo reformismo: argumento a partir do caso brasileiro recente de conflito distributivo capital/trabalho Pedro Henrique Santos Queiroz.

CONSELHO NACIONAL DE JUSTIÇA. 2017. Despesa com o judiciário cresce, mas o custo por habitante cai em 2016. Disponível em http://www.cnj.jus.br/noticias/cnj/85362-despesa-do-judiciario-cresce-mas-o-custo-por-habitan te-cai-em-2016. Acessado em 28/05/2018

DIEESE. 2016 Balanço das negociações dos reajustes salariais de 2015. Estudos e Pesquisas, n 83: 1-23.

ESTADO DE SÃO PAULO. 2015. Benesses fiscais dobram no governo Dilma e passam de R\$ 400 bilhões. Disponível em https://economia.estadao.com.br/noticias/geral,benesses-fiscais-dobram-no-governo-dilma-e-pa ssam-de-r-400-bilhoes, 10000003973 . Acessado em 28/05/2018

FOLHA DE SÃO PAULO. 2015. Dilma deu R\$ 458 Bilhões em desonerações. Disponível em http://www1.folha.uol.com.br/mercado/2015/09/1678317-dilma-deu-r-458-bilhoes-em-desone racoes.shtml. Acessado em 28/05/2018

FRASER, N e HONNETH, A. 2003. Redistribution or Recognition?: A political-philosophical Exchange. 1 ed. London, Nova York, Verso, 276 p.

FRIEDMAN, M. 1977. Capitalismo e liberdade. [S.I], Artenova, 172 p.

GORZ A. 2004. Misérias do presente, riqueza do possível. 1 ed. São Paulo, Anablume.

GLOBONEWS. 2014. Guido Mantega e Armínio Fraga debatem no GloboNews Miriam Leitão. Disponível em

http://g1.globo.com/globo-news/noticia/2014/10/guido-mantega-e-arminio-fraga-debatem-no-globonews-mir iam-leitao.html. Acesso em 28/08/2018

HADDAD, F. 2017. (Des)Ilusões liberais. FHC, Lula e a ficção histórica de Marcos Lisboa. Disponível em http://piaui.folha.uol.com.br/materia/desilusoes-liberais/. Acesso em 28/08/2018 IBRE/FGV. 2018. Um ano de blog do IBRE: Os artigos mais lidos. Disponível em http://blogdoibre.fgv.br/posts/um-ano-de-blog-do-ibre-os-artigos-mais-lidos. Acesso em $28 / 08 / 2018$ 
Renda básica universal como programa para um novo reformismo: argumento a partir do caso brasileiro recente de conflito distributivo capital/trabalho Pedro Henrique Santos Queiroz.

IPEA. 2012. A década inclusiva (2001 a 2011): Desigualdade, pobreza e políticas de renda. Comunicados do IPEA, n 155: p. 1-44. . 2017 Metodologia de cálculo do indicador IPEA Mensal de FBCF. Disponível em http://www.ipea.gov.br/cartadeconjuntura/index.php/2017/11/17/metodologia-de-calculo-doindicador-ipea-mensal-de-fbcf/. Acesso em 28/08/2018

LISBOA, M. 2017. Outra História. Uma resposta a Fernando Haddad. Revista Piauí. Disponível em http:/ / piaui.folha.uol.com.br/materia/outra-historia/. Acesso em 28/08/2018

MANTEGA, G. 2012. O Primeiro ano da nova matriz econômica. Valor Econômico. Disponível em http://www.valor.com.br/brasil/2945092/o-primeiro-ano-da-nova-matriz-economica. Acesso em $28 / 08 / 2018$

MARX, K. 2013. O Capital. Crítica da economia política. 1 ed. São Paulo, Boitempo, 894 p. MARTINS, J. S. O cativeiro da terra. Nova edição revista e ampliada. São Paulo, Contexto, 2010. PESSÔA, S. 2017. Uma história de dois planos Marshall. Folha de São Paulo. Disponível em http://www1.folha.uol.com.br/colunas/samuelpessoa/2017/05/1883849-uma-historia-de-doisplanos-marshall.shtml. Acesso em 28/08/2018

PIKETTY, T. 2014. O Capital no século XXI. 1 Edição, Rio de Janeiro, Intrínseca, 669 p. SILVA, J P. 2008. Trabalho, cidadania e reconhecimento. 1ed São Paulo, Anablume, 165 p. 2014 Por que renda básica? 1 ed, São Paulo, Anablube, 194 pg

SINGER, A. 2012. Os Sentidos do lulismo: reforma gradual e pacto conservador. 1. Ed. São Paulo, Companhia das Letras, 276 p.

2015. Cutucando onças com varas curtas. O ensaio desenvolvimentista no primeiro mandato de Dilma Rousseff (2011-2014). Novos Estudos, v.102, jul. p 39-67.

SUPLICY, E. M. 2013. Renda de Cidadania. A saída é pela porta. 7. Ed, São Paulo, Cortez.,463 p. VALOR ECONÔMICO. 2017. Renda básica no país custaria 4,6\% do PIB e reduziria pobreza em 11,6\%, diz FMI. Disponível em http://www.valor.com.br/brasil/5166768/renda-basica-no-pais-custaria-46-do-pib-e-reduziria-p obreza-em-116-pontos-diz-fmi. Acesso em 28/08/2018. 
Renda básica universal como programa para um novo reformismo: argumento a partir do caso brasileiro recente de conflito distributivo capital/trabalho Pedro Henrique Santos Queiroz.

WORLD ECONOMIC FORUM. 2017 A Basic Income for All: Dream or Dellusion. Disponível em

https://www.weforum.org/events/world-economic-forum-annual-meeting-2017/sessions/a-basi c-income-for-all-dream-or-delusion. Acesso em 28/08/2018 